\title{
A Cognition Study on the Mode of Historical Urban Space
}

\author{
W. J. Kong
}

\begin{abstract}
In China, the conservation system of urban historical and cultural heritage includes three parts: the culture relic protection site, the historical and cultural block and the historical and cultural city. According to the evaluation system, the conservation lists are mainly based on whether the heritage is complete or not and its historic value, the relics are classified into three grades as the National Level, the Provincial Level and the Municipal Level. However, a large number of historic urban space with incomplete remains and inadequate value couldn't be listed in restoration. Thus untitled historic space cannot attach enough importance and conservation resulted in disappearance not only in the development of the cities, also in people's memory.

With a comprehensive understanding of the historic space, this paper suggests five existing status of historic information in urban space through a mode system which consists of 3 criterions: the form, the function and the status. Comparing the prototype with the present situation of the historic space, five modes of various environmental elements could be estimated according to the criterion, including the prototype mode, the fragment mode, the structure mode, the symbol mode and the information mode. It establishing the heritage study with a background of authenticity and integrity as to prevent a single and one-sided conservation method.
\end{abstract}

Index Terms-Historical urban space, mode, urban heritage, cognition study.

\section{INTRODUCTION}

In our country, antique counterfeit has been constructed everywhere. Claimed as conserving culture heritage, restorations of vanished relics and removed city walls are telling false information of history, mentioned by Y.S. Ruan in Wenhui Daily in 2004. At present a 'city retro boom' waved one after another that has continuously aroused rejections and controversies within the academics, public opinions and even common consumers. Many people consider these actions that removing real historical dwellings to build disappeared ancient cities, are actually destroying under the fame of protection. And experts are strongly opposed to this behavior of imitation of the past 'cultural relics', antique reconstruction of the content does not contain real historical information with nothing about historical and cultural value [1]. These problems one-sidedly reflect that our heritage conservation work is in a confused period that the issue about the historical space of the ancient city should be restored or adaptive adjustment is been discussing. But the basic target is to clarify what is the historical space and where and how the city space containing them.

Manuscript received October 15, 2017; revised December 27, 2017. This work was supported by NFSC51278211 ( The Theory and applied research of Four Dementional City) and NFSC51708235(Collective Conservation Method Of Rural Settlements In The Regional Perspective).

W. J. Kong is with Huazhong University of Science and Technology, Wuhan. China (e-mail:julia8702@hust.edu.cn).
In China, the conservation system of urban historical and cultural heritage includes three parts: the culture relic protection site, the historical and cultural block and the historical and cultural city. The cognition of the heritage depends on the built time, the scale and the historical scene of heritage, for what the corresponding methods and strategies are promoted. According to the evaluation system, mainly based on whether the heritage is complete or not and its historic value, the relics are classified into three grades as the National Level, the Provincial Level and the Municipal Level. However, a large number of historic urban space with incomplete remains and inadequate value couldn't be listed in restoration [2]. Thus untitled historic space cannot attach enough importance and conservation resulted in disappearance not only in the development of the cities, also in people's memory.

Obviously the cognition of the historic urban space is how the people or the experts define the heritage, which determines what to conserve or protect. With a comprehensive understanding of the historic space, this paper finds five existing status of historic information in urban space through a mode system, establishing the heritage study with a background of authenticity and integrity as to prevent a single and one-sided conservation method.

\section{THE CONCEPT AND CRITERION OF THE MODE}

\section{A. The Concept of the Mode}

The mode of urban historical space indicates the status of various types of urban space, still conveying historical information in nowadays. It involves several connotative meanings. Firstly it refers to the historical information projected onto today's material environment which offers a direct feeling of real history to the public. Secondly it is the objective present of historical space with authenticity and accuracy, so people could draw a conclusion as it's actually the same as past or no longer as it used to be. Ultimately it embodied the definition of historic information at present, and identifiability of various space elements, clearly expressing a certain built time.

\section{B. The Classified Criterion of the Modes}

The historic space is considered as a complex system which is commensurate as a consequence of a long term living environment. For the space itself, there are many aspects that form its integrity. so this paper suggests a criterion from 3 aspects: form, function and status. The form mainly determined by the judgment of a complete structure or partial fragments. The function indicates whether the space still carries the original function or just a memorial symbol without former usage. The existing state can be told with recognizable real space or proceeding public memories.

The form is the direct feeling of the morphological feature 
which can be sensibly touched, seen and recognized. It consists of the structure and the content. The structure is regarded as an interactive role in the complex urban space, combining partial pieces into an entirety, reflecting the inner relationship and regulation. The content is the filling within the structure as the entity of the material space, as well as the base of hosting space function. From the perspective of figure-ground relation, the content can be seen as the figure whiles the structure as the ground. As long as the structure keeping stable, an unaltered cognition is maintained as the prototype even though the content has changed.

The form reflects a feature of hierarchy. Human body is a same complicated case to analogy: the skeleton is the structure while muscles and organs are the contents; in next layer, as the smaller object-muscles, the vessels can be seen as the structure while the cells as the contents. Same in the whole city space, the streets and lanes play a part as the structure while the blocks and clusters as the content; in smaller space as the courtyard, the layout as the structure while the individual buildings as the contents. This paper mainly focuses on the urban space, further analyze on individual buildings won't be extended.

The function is the available meaning of the space and the actual relationship between environments and human activities. As the close connection interwoven with space and events mentioned by Alexander, the Place, containing social activities, is included in the six elements of narration. Various environments of cities are contributed for functional requirements. Such certain space would have become a memorial of prototype since the initial function were altered, although it might have changed into other usage.

The status denotes the way transmitting historical messages, mostly can be defined as two kinds, tangible terms and intangible terms. The former includes constructions such as buildings, bridges, city walls, roads, etc. and the latter includes names, languages, traditional customs and other messages conveying historical information. Usually the intangible terms comes to public with the tangible parts and turns to be importance as collective memory after the tangible parts have disappeared. The status especially like collective memory is a passive acceptance - first signal to newcomers formed by present communities which quite differs from the other two aspects above.

Comparing the prototype with the present situation of the historic space, five modes of various environmental elements could be estimated according to the criterion, including the prototype mode, the fragment mode, the structure mode, the symbol mode and the information mode. (Table I) (Fig.1)

TABLE I: THE MODE CLASSIFIED CRITERION OF HISTORICAL SPACE

\begin{tabular}{lllllllll}
$\begin{array}{l}\text { Classified } \\
\text { criterion } \\
\text { Mode type }\end{array}$ & Form & & Function & Status & & Example \\
\hline $\begin{array}{l}\text { The prototype } \\
\text { mode }\end{array}$ & $\begin{array}{l}\text { Coherence with } \\
\text { original }\end{array}$ & complete & $\begin{array}{l}\text { Original } \\
\text { usage } \\
\text { changed }\end{array}$ & or & $\begin{array}{l}\text { Materiali } \\
\text { ty }\end{array}$ & $\begin{array}{l}\text { Name or other } \\
\text { historical } \\
\text { information }\end{array}$ & $\begin{array}{l}\text { The } \\
\text { Forbidde } \\
\text { n City }\end{array}$ \\
\hline $\begin{array}{l}\text { The fragment } \\
\text { mode }\end{array}$ & $\begin{array}{l}\text { Coherence with } \\
\text { original }\end{array}$ & $\begin{array}{l}\text { Partial } \\
\text { changed } \\
\text { vanished, } \\
\text { disappeared }\end{array}$ & $\begin{array}{l}\text { Original } \\
\text { usage } \\
\text { changed }\end{array}$ & or & $\begin{array}{l}\text { Materiali } \\
\text { ty }\end{array}$ & $\begin{array}{l}\text { Name or other } \\
\text { historical } \\
\text { information }\end{array}$ & $\begin{array}{l}\text { Stone } \\
\text { City } \\
\text { Wall, }\end{array}$ \\
\hline $\begin{array}{l}\text { The structure } \\
\text { mode }\end{array}$ & $\begin{array}{l}\text { Coherence with } \\
\text { original }\end{array}$ & Disappeared & $\begin{array}{l}\text { Original } \\
\text { usage } \\
\text { changed }\end{array}$ & or & $\begin{array}{l}\text { Materiali } \\
\text { ty }\end{array}$ & $\begin{array}{l}\text { Name or other } \\
\text { historical } \\
\text { information }\end{array}$ & $\begin{array}{l}\text { The } \\
\text { green } \\
\text { ring, }\end{array}$ \\
\hline \hline
\end{tabular}

\begin{tabular}{|c|c|c|c|c|c|c|}
\hline & & & & & & Hefei \\
\hline $\begin{array}{l}\text { The symbol } \\
\text { mode }\end{array}$ & Disappeared & $\begin{array}{l}\text { Relics, partial } \\
\text { rebuilt }\end{array}$ & $\begin{array}{l}\text { Function } \\
\text { disappeared, } \\
\text { meaningful } \\
\text { memorial }\end{array}$ & $\begin{array}{l}\text { Materiali } \\
\text { ty }\end{array}$ & $\begin{array}{l}\text { Name or other } \\
\text { historical } \\
\text { information }\end{array}$ & $\begin{array}{l}\text { Tiananm } \\
\text { en, } \\
\text { Beijing } \\
\text { The } \\
\text { small } \\
\text { east gate, } \\
\text { Cicheng }\end{array}$ \\
\hline $\begin{array}{l}\text { The } \\
\text { information } \\
\text { mode }\end{array}$ & Disappeared & Disappeared & $\begin{array}{l}\text { Function } \\
\text { disappeared, } \\
\text { meaningful } \\
\text { memorial }\end{array}$ & $\begin{array}{l}\text { disappear } \\
\text { ed }\end{array}$ & $\begin{array}{l}\text { Name or other } \\
\text { historical } \\
\text { information }\end{array}$ & $\begin{array}{l}\text { Fucheng } \\
\text { Gate, } \\
\text { Beijing }\end{array}$ \\
\hline
\end{tabular}

\section{Drototype prototyped part $\begin{gathered}\text { Prototype } \\ \text { mode }\end{gathered}$
$\begin{gathered}\text { Fragment } \\ \text { mode }\end{gathered}$ $\begin{gathered}\text { Structure } \\ \text { mode }\end{gathered} \quad \begin{gathered}\text { Symbol } \\ \text { mode }\end{gathered}$}

Fig.1. A graphical explanation of historical space mode

\section{ANALYSIS OF MODES FOR URBAN HISTORIC SPACE}

The historic cities were formed by etiquette system, functional requirements, religious belief which projected on artificial environment, and have become complicated, diversified, scattered under modern construction [3]. A certain spatial element could be a single mode or multiple modes. Along with the analysis of five different modes, all kinds of space elements can find their modes, among which the distinctions can be told.

\section{A. The prototype mode}

The prototype mode indicates the space containing a complete historical message with an original and well-preserved situation. Although the function would have changed, this kind of element won't have much change in the long-term by holding a stable structure and content and a widely recognized name. Most historic sites in prototype mode are listed and protected buildings as cultural and historical unites, in which partial material could has changed by traditional practice of continuously renewing, fixing and repair actions. In the urban historic elements, the prototype modes are mainly included in natural environment, landmarks, traditional dwellings, traditional markets and city walls.

Natural environment determined the site selection since ancient times. In Chinese Fengshui theory, the ideal geographical site should consist of mountains on three sides and water in the front, left mountains as a dragon, right mountains as a tiger, and front mountains as a desk. From the scientific perspective, the traditional law actually reflects wind corridor, sunlight, water system and other natural condition. Despite part of the historical mountains and rivers have been surrounded by the built up area as rapid expansion of the city, the natural elements are hardly modified because of the fear to the natural under the harmonious concept.

Individual historic buildings and a coessential group of historic buildings of officially preserved sites mostly belong to this prototype mode, especially public constructions such as political, ritual and religious buildings. Built by durable and quality materials such as time-proof woods, inheriting the original function, this kind of spaces are hardly changed and well preserved. Take the Big Goose Pagoda as example 
in Xi'an, issued as one of the first batch of National culture and historical sites in 1961, it is consisted by a structure formed in Tang Dynasty (7th century) and a content body in Ming Dynasty (14th century) as the prototype. Even the tourist function has taken place of the Buddhism, it's still containing the deep Buddhist culture.

\section{B. The Fragment Mode}

The fragment mode refers to general preserved historic spaces, containing an original skeleton and divided pieces of contents, a partial modification of function, which can be recognized as decrease or fragment of the prototype. This mode exists in all kinds of space elements, and this part takes the boundary and skyline for further explanation.

Historical boundaries are generally existing as the fragment mode. The boundaries of ancient cities in our country include city walls, moat, gates and gate towers. Before Ming Dynasty (14th century), the walls were built by rammed earth, and reinforced by wrapped grey bricks. As a result of follow-up changes reflected by natural weathering, wars and modernization ethos, most of the ancient city wall only left fragments. The wall of outer city in Nanjing once owned an original round wall of 13 gates and 2 water gates, now it remains as seven intermittent pieces with a contrast of 4 gates and only one water gate. Even though, people could conclude the gestalt from the remains. In some other cities, the past boundaries including city walls and moats, most belong to the situation that only moat remains, outlining the cities' shape while the walls have filled into roads(Fig. 2).

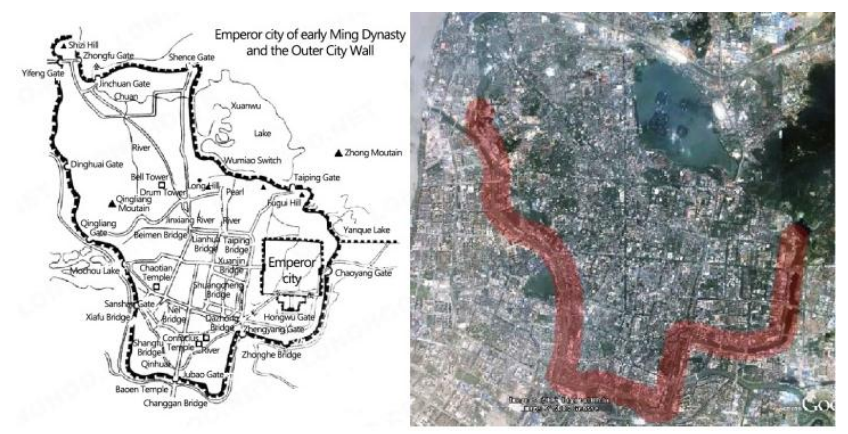

Fig. 2. The contrast between the historical message and the fragmental remains of ancient city wall in Nanjing.

Skyline is the most intuitive facade of historic space element overlaying by tangible architectures of each period, which belongs to fragment mode result from its fragile and changeful feature. Although an obvious skyline difference caused by architecture structure existing between the east and west, vivid vs. gentle, there is a common reason of rise and fall formed by large-scaled public buildings, such as political, ritual and religious constructions.

Attributed to increasing height behaved by modern constructions, it's difficult to see the pristine skyline of Chinese ancient cities sheltered under the foreground and background. For example the skyline of the imperial city of old Beijing is no longer magnificent as it was (Fig.3). The waving rooves, ups and downs, have disappeared along with quadrangle dwellings, meanwhile the sky has been divided by skyscrapers and the Forbidden City looks like a tiny model with a contrast of new buildings. Today well-preserved skylines in domestic cities mainly lay in national culture and historical cities, such as Langzhong, Pingyao, Lijiang ancient city, no exception owning a skyline of continuous dwelling roofs, towering public buildings and natural mountains as environmental background, basically reflecting an original appearance.

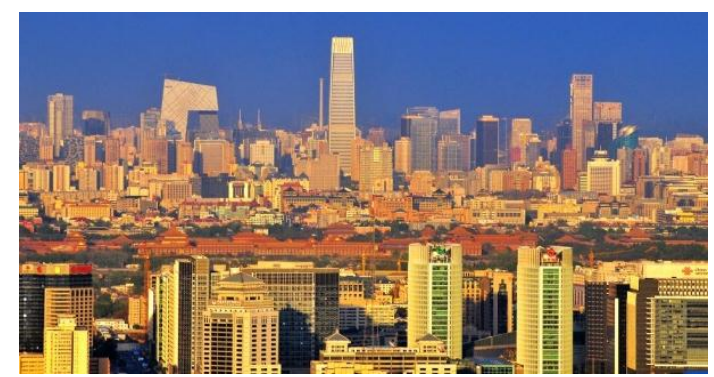

Fig. 3. The skyline of Beijing, the Forbidden city hidden in the skyscrapers.

\section{The Structure Mode}

The structure mode refers to those owned an original structure, but the content has almost vanished while the new fillings have replaced the original texture and measure. Similarly revealing historical information, the structure mode essentially differs from the fragment mode above. The fragment mode can be regarded as the diminishment of the prototype, as the structure mode emphasizes structural feature unrelated to the original content. The structure mode generally exists in the boundary, road system, central axis, traditional dwelling courtyards.

Boundary in structure mode happens in many ancient cities, which has been emerged in replacement of roads and public greenbelts. This modification of taking down walls to paving can be traced back to the 1950's. For instance, the present Nantong Road in Yangzhou stands in part of the old city wall, and the Taizhou Road is the former situation of the old east wall. Another example in Hefei, transformed into the green ring around the city, the structure reflects a whole shape of boundary by landscape practice.

Road system is the city's skeleton which belongs to the typically structure mode. It's hard to modify the road system in the city, but a number of newly planned roads have taken place as a purpose to meet the demands of modern traffic style. Such as a road system of three upright with four crossing in Cicheng ancient city, the original scale roads together with a wide street of 1990's, same as a historical imprint, constitutes the road system (Fig. 4).

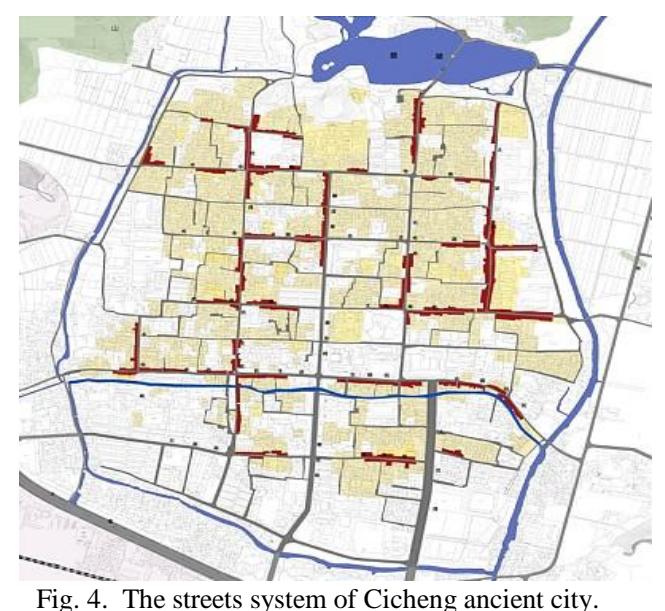

Central axis is the main to express the social order of feudal ritual in old China, governing the symmetrical layout 
and clearing the class order. Nowadays many other meaning has been derived out from the central axis. First of all, it has become the psychological city central, is the place major activities taken place. Secondly as an important city image, it converts the characteristic and spirit. At last, its traffic function impacts on planning and extending of subsequent roads, further influences the developing area. The central axis of Beijing formed in the Yuan dynasty(13 AC) and extended to the north and south since Ming to Qing dynasty (14 AC-19AC). After the founding of new China, constructions in the central axis including Yongding Gate, Zhengyang Gate, Wupailou building, Changan East Gate, Changan West Gate and Di'an Gate, were removed instead by significant buildings as Great Hall of the People, the Monument to the People's Heroes, the national flag station and Mausoleum of Mao Zedong. Today, with the constant development of the city, central axis is still playing a leading role in the process of spatial growth.

\section{The Symbol Mode}

The symbol mode refers to the relics and partial rebuilt by means of modern technique and materials. Symbolically representing the sense of the space, this mode is the memorial form of memory, which function bears nothing related to the originals. Compared with other modes, it focuses on more meaningful commemorative expression, rather than the prototype form of ontology, as some landmarks and usable reconstructions.

Landmark is the geographical symbol in psychology. Despite as the modern replacement of the originals, it contains the intuitive cognition of the certain site and region. Like Yellow Grain Tower in Wuhan, mentioned in famous sentence of Cui Hao's poet in tang dynasty, which reveals its important history status. Later, as wars come and go, the tower ruined and rebuilt, the current version was built in 1985 , totally a modern structure inside wearing a Qing's model of 1860 's. For the convenience of tourists to overlook upstairs, even an elevator was built in it. For Wuhan, the Yellow Grain Tower is a typical sample of symbol mode, forges a role of culture and spirit far more than the structural value itself.

Nowadays in order to reproduce the historic information of boundaries, some ancient cities symbolically present landscape to show the image of city wall or the wall gate, rather than rebuilt a fake antique. As the old city of Cicheng ancient city which has been removed for many years, a northern fraction of the relic is designed as part of Cihu garden, and a length of southeast part is constructed by steel frame, while the small east gate is a modern construction built by steel frame and stalinite in the primary site. All these methods are converting the historic information by symbolic landscape (Fig. 5).

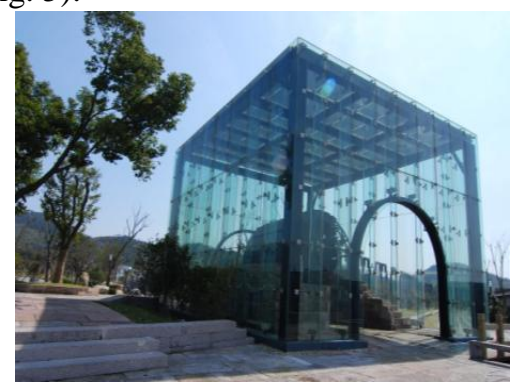

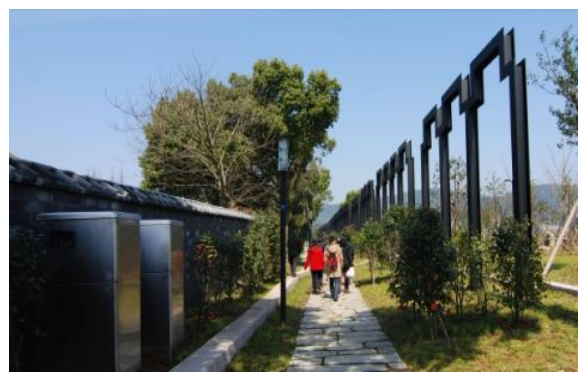

Fig. 5. The Small East Gate of a landscape type in Cicheng ancient city.

\section{E. The Information Mode}

The information mode denotes those disappeared places maintaining an old name, like road name, time-honored brand and other virtual messages. Without material substance its historical information was hardly felt by sense organs. Kept as collective memory, the information mode is an indivisible part to keep cognitive integrity of the city.

The road names in Yangzhou ancient city contain a large amount of historical information: Canfu Road is named after the ancient yamun of local government four hundred years ago; Bingsima lane is the former site of local armed force; Shuizhixiang lane is named after the landmark of a great fire wall with a Hanzi Shui embedded in the southern section of the lane; Litou street comes from geomorphic characteristics that the terrain looks like a plough; and some roads are named after military facilities such as Xiaochang, Dongying, Guqiting, etc. In addition, there are countless lanes called after the old gates, temples, manual workshops, famous old shops. Take Taiyuan city as example, Shangxiaoqiang and Xixiaoqiang streets stand the former site of city wall of prefectural Taiyuan; as the old private palace garden of king of Jin, Xinghualing has become the district name; the road of Jihuying used to be called the front street of Guangchangfu, the modification comes from a folklore that an emperor once killed a tiger in this place. As a pronoun of the certain place, this mode widely exists in our common life, approximately indicating the disappeared former sites through toponymy explanations [4].

\section{The Feature Analysis of the Modes}

\section{A. Generic Space Tends to be Similar Modes}

Compared with various elements of urban historic space, it's easy to see a sense of similarity between the modes and generic space. For example, space elements related to the whole city, such as the natural environment, boundary, road system and central axis, mainly belong to the fragment mode and structural mode; and thus related to the material surrounding usually lie in various modes, as dwellings, landmarks and commercial space.

As the space is consisted by inner layers, the factors are altered by the changes of contents and texures. Take a case of structural mode - the central axis, the location and direction is stable and the change mainly exists in the length extension and the width broaden.

\section{B. Space in Structural Mode Appears Stable and Unique While the Contents Tends to be Changeable and Diversiform}

To explain the integrity of historic urban space by Gestalt 
theory, people can arrange the factors' sequence in visual environment by mind to feel the entirety and continuity. Even if the content has partly changed or vanished, it hardly alters the whole feature as the structure could still construct the gestalt.

The space structures of historic cities were not only orderly restricted by power etiquette, but also influenced by laws of transportation, social association and trades, finally formed in a stable shape through evolution and selection. The content elements were mainly formed by terrain, climate and function, less restricted by political and ritual rules, revealing an unconstrained and changeable feature. As a result of the stable structure and various contents, ancient cities in our country give a common character of both feudal planning thought and a philosophy of harmonious unity gathering the nature and human, and different styles of buildings and region view coming from occasions caused by profusion events of common lives.

\section{The Changeability of the Mode}

Rarely belonging to an absolute stable condition, the type of the modes would change as function alteration and subsequent social environment. Form follows the function, and the function was to meet people's demands, so the transform is to make the working process more comfortable and convenient. That is the reason sundry of urban space existing as a result of different demands.

Continue the analysis, the historical prototype is the form contained the original function. On the other hand, when the original function disappeared or altered, the prototype should have changed; if the form had not changed, it should have turned to host the historic memory, more broadly, as another usage or function.

\section{CONCLUSION}

Researches on urban historical space have been keen on archaeologically tracing back, mostly as a speculation to the past, playing a reference role to the conservation work [5]. As the urban history is a growing process, evolution in each part owns particular reasons itself, seems as a natural selection. The present status should be treated objectively, while preserving and disappearing as well as a fact of historical space.

In the searching process for space information, the remains of prototype mode and fragment mode are easily been recognized, in the contrast the structure mode, symbol mode and information mode tends to be ignored, which couldn't be felt directly, but also excepted by the conservation list, might disappear in the collective memory. In order to tell a comprehensive information of history with respect to objective development, and to avoid excessive rebuilding, it's necessary to find and reveal the invisible historical space with a suitable aspect, which makes the renewing planning more justified, and plays an contributing role in creating fine historical environment.

\section{REFERENCES}

[1] Z.. Wang, "Urban restoration competition," New Business Weekly, vol. 4, pp. 48-50, 2012

[2] S. Zhang, Conservation Science Introduction of Historic Cities, Shanghai: Tongji University Press, 2008

[3] J. Dong, Construction History of Chinese Cities, $3^{\text {rd }}$ ed. Beijing: China Architecture \& Building Press, 2004

[4] Y. He, Urban Memory and Culture Heritage, Urban Planning, pp. 89-92,Sep. 2005

[5] Y. He and J. S. Li, "Temporal study on urban space," Urban Planning, vol.36, no.11, pp. 9-28, Nov. 2012.

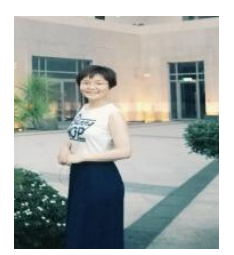

W. J. Kong is a candidate in Urban Planning of Huazhong University of Science and Technology, School of Architecture and Urban Planning, China, with a master degree (2012) in this field in the same school, majoring in the urban and rural heritage conservation.

Weijie's expertise includes heritage conservation, urbanand rural development and construction, heritage impact assessments, the impact on heritage sites and relevant countermeasures.

She is a research assistant in Huazhong University of Science and Technology, with more than 7 years of experience in urban and rural area conservation of historic and cultural heritage. She was the Project Leader for following projects: Conservation Planning of Taogong Village, Dongqian Lake, Ningbo City, China, 2016. Guidelines for Village Planning of Hanling Village, Dongqian Lake, Ningbo City, China, 2016.Guidelines for Implementary Planning of Hanling Village, Dongqian Lake, Ningbo City,China, 2015. Research on Spatial Characteristics of Traditional Villages around Dongqian Lake, NingboCity, China, 2014. Constructive and Implementary Planning of Xiashui Village, Dongqian Lake, Ningbo City,China, 2013. She also has some academic publications: Conservation and Development of "Atypical Traditional Village",Urban Planning, accepted (2017), "Geographical Texture Recognition and Repair of Northern Section of the Old Bund in Ningbo". New Architecture, June (2017). Her current research is about the rural living environment of Dongqian Lake, Ningbo, which is her Ph.D. dissertation. 